\title{
TINJAUAN ASPEK KELAYAKAN ELEMEN PEMBENTUK RUANG KOMUNAL DI TAMAN MONUMEN 45 KOTA PEKALONGAN
}

\author{
Moch Fathoni Setiawan ${ }^{1}$, Andi Purnomo ${ }^{2}$ \\ ${ }^{1,2)}$ Jurusan Teknik Sipil, Prodi Arsitektur Fakultas Teknik, Universitas Negeri Semarang (UNNES) \\ email: fathoni@staff.unnes.ac.id ; mas_andipoer@yahoo.com
}

\begin{abstract}
Taman Monumen 45 is one of the city park in Pekalongan City, in which there are statues of the heroes as monument to commemorate the services of the heroes. In this park there are also garden element in shape of hard elements and soft elements. Some hard elements are sitting group, pedestrian area, sports area, and the statue of the heroes (sculpture). The hard elements are referred to support the communal activity for the citizens of Pekalongan. They are functioned as for gathering and chatting, lounging, skateboarding and BMX styling. This study aims to assess the feasibility aspects in Taman Monumen 45 in Pekalongan City. From the research, it was revealed that there are some elements of the park that do not meet the eligibility aspect as constituting elements of communal space. It can be seen from the condition of these elements, either hard material or soft material that is still less maintained and is not in accordance with its function.
\end{abstract}

Keywords : city park, constituting elements, communal space

\begin{abstract}
Abstrak: Taman Monumen 45 merupakan salah satu taman kota di Kota Pekalongan yang mana di sana terdapat patung pahlawan sebagai monumen untuk mengenang jasa para pahlawan. Pada taman ini juga terdapat elemen taman berupa elemen keras (hard material) dan elemen lunak (soft material). Elemen keras pada taman ini diantaranya sitting group, area pedestrian, sport area, dan patung pahlawan (sculpture). Elemen keras tersebut sebagai salah satu pendukung aktifitas komunal bagi warga Kota Pekalongan seperti berkumpul, mengobrol dan duduk santai, tempat bermain skateboard dan $B M X$ style. Penelitian ini bertujuan untuk mengkaji aspek kelayakan pada Taman Monumen 45 di Kota Pekalongan. Dari hasil penelitian, terungkap bahwa ada beberapa elemen taman yang tidak memenuhi aspek kelayakan sebagai pembentuk elemen ruang komunal. Hal ini dapat dilihat dari kondisi elemen-elemen tersebut, baik hard material atau soft material yang masih kurang terawat dan tidak sesuai dengan fungsinya.
\end{abstract}

Kata kunci : taman kota, elemen pembentuk, ruang komunal.

\section{PENDAHULUAN}

Taman Monumen 45 adalah salah satu taman aktif di tengah Kota Pekalongan yang di dalamnya terdapat patung pahlawan sebagai monumen untuk mengenang jasa para pahlawan. Pada taman ini terdapat elemen taman berupa elemen keras (hard material) dan elemen lunak (soft material). Elemen keras pada taman ini diantaranya sitting group, area pedestrian, sport area, dan patung pahlawan (sculpture). Elemen keras tersebut sebagai salah satu pendukung aktifitas komunal seperti berkumpul dan duduk santai, tempat bermain skateboard dan BMX style. Pada area pedestrian saat malam hari ramai para Pedagang Kaki Lima (PKL) yang berjualan. Namun, tidak tersedianya area khusus untuk pedagang kaki lima (PKL) sehingga membuat pedagang kaki lima berjualan di pinggir jalan dan di area jalur pedestrian. Selain elemen keras yang mendukung aktifitas komunal di Taman ini juga terdapat elemen lunak antara lain tanaman pelantai, tanaman peneduh, tanaman perdu, dan tanaman pengarah. Keberadaan elemen lunak ini memberikan nuansa sejuk dan rindang yang memberikan kenyamanan untuk beraktifitas di dalamnya. Kondisi fisik elemen 
keras dan elemen lunak yang layak merupakan salah satu sarana penting yang mendukung aktifitas komunal didalamnya. Berdasarkan kondisi tersebut perlu adanya studi yang mengkaji mengenai aspek kelayakan elemen taman sebagai pembentuk ruang komunal pada taman ini.

Menurut Lewis, 1973 dalam Bell (2001), taman dapat menambahkan hubungan sosial dalam komunitas dengan menyediakan tempat pertemuan dan kesempatan bagi orang-orang untuk berkumpul bersama.

Hal ini sejalan dengan fungsi utama taman yang menurut Woolley (2003) dan Simonds (1994) memiliki 2 fungsi yaitu: 1) Fungsi estetis, dimana taman dapat membentuk keindahan sebuah kota, terutama dengan mempertahankan kealamiannya. 2) Fungsi sosial, dimana taman menjadi tempat bagi berbagai macam aktivitas sosial seperti berolahraga, rekreasi, diskusi dan lainlain. Fungsi ini pada dasarnya menjadi kebutuhan warga kota sendiri yang membutuhkan ruang terbuka untuk bersosialisasi sekaligus menyerap energi alam.

Menurut Arifin (2006), dalam perancangan taman perlu dilakukan pemilihan dan penataan secara detail elemenelemennya, agar taman dapat fungsional dan estetis. Elemen penyusun taman yaitu hal-hal yang digunakan untuk menyusun taman sedemikian rupa sehingga tercipta keselarasan dan bisa dinikmati. Elemen penyusun taman sangat beragam, tetapi untuk memudahkan dalam pengenalan, sebaiknya dikelompokkan menjadi 2, yaitu elemen keras dan elemen lunak. Elemen keras yaitu tampilan penyusun taman yang bersifat keras.
Umumnya, elemen keras juga merupakan benda mati. Sementara, elemen lunak yaitu segala hal sebagai penyusun taman yang bersifat lunak. Umumnya, elemen lunak merupakan mahluk hidup, baik berupa tanaman maupun hewan. Namun, dari porsinya, tanaman sangat mendominasi sebagai elemen lunak penyusun taman.

Elemen keras pada sebuah taman juga sering dikenal dengan ornamen taman. Kehadiran elemen dekoratif ini sangat berpengaruh pada tampilan taman secara keseluruhan. Elemen keras sebagai aksen pada taman memang sangat beragam. Masing-masing memiliki fungsi dan memberikan nilai seni yang berbeda. Beberapa jenis elemen keras yang kerap digunakan yaitu patung, lampu taman, tempayan, kolam dan air terjun, gazebo, jalan setapak, batu-batuan, ayunan, dan pernakpernik dari gerabah.

Elemen lunak terdiri dari tanaman dan binatang. Namun, dominasi tanaman tentunya lebih banyak. Kegunaan tanaman dalam tata tanam, antara lain : penutup tanah (ground cover atau surfacing), pengendali pandang atau tabir (screen), tanaman difungsikan sebagai pembatas (pagar/dinding), tanaman peneduh (shelter), pengendali unsur iklim dan polusi, serta sebagai nilai keindahan (aesthetic values).

\section{METODOLOGI}

Eksplorasi data dilakukan pada elemen-elemen taman yang ada di Taman Monumen 45 Kota Pekalongan. Peneliti survey langsung ke lapangan untuk meneliti kelayakan elemen dengan cara mengamati 
langsung dan mengukur beberapa elemen untuk mengetahui data fisik yang akurat. Dari hasil pengematan langsung tersebut peneliti membagi elemen yang ada di Taman Monumen 45 Kota Pekalongan menjadi 2 elemen yaitu elemen keras (hard material) dan elemen lunak (soft material). Dari hasil pengelompokkan elemen tersebut kemudian data diproses dengan cara membandingkan data lapangan dengan standar elemen taman. Dari hasil analisa tersebut dapat diketahui layak atau tidaknya suatu elemen dari penilaian atau skoring yang dikelompokkan menjadi 4 kriteria, antara lain: keindahan, keterawatan, ketergunaan, dan dimensi. Bobot penilaian maksimal pada masing-masing kriteria adalah 10 nilai, yang kemudian diambil nilai rata-rata pada tiap elemen. Setiap elemen yang memiliki nilai $\leq 5$ dianggap tidak memenuhi standar (tidak layak) dan yang memiliki nilai > 5 dianggap memenuhi standar (layak). Kemudian hasil kesimpulan skoring diambil dari skor rata-rata yang diperoleh dibagi dengan jumlah elemen standar yang ada. Dari hasil tersebut akan terlihat hasil akhir penilaian yang akan menentukan elemen tersebut layak atau tidak sebagai elemen pembentuk ruang komunal di Taman Monumen 45 Kota Pekalongan.

\section{HASIL DAN PEMBAHASAN}

Taman Monumen 45 ini termasuk dalam kecamatan Pekalongan Barat dengan luasan $\pm 7.315 \mathrm{~m}^{2}$. Taman ini merupakan taman kota karena letak taman ini berada di pusat kota hanya saja luasannya tidak memenuhi standar luasan taman kota. Elemen pada taman Monumen 45 Kota Pekalongan berdasarkan kesan yang ditimbulkan dibagi menjadi 2 macam yaitu: Elemen Keras (Hard Material), dan Elemen Lunak (Soft Material).

\section{Elemen Keras (Hard Material)}

a. Sitting Group

Sitting group lengkung dan segi delapan banyak di area sekitar taman namun letaknya berada di tengah taman dan harus menginjak rumput (tanpa ada stepping stone). Hal ini menjadikan masalah karena apabila kondisi tanah becek bisa menjadi kendala untuk menuju ke sitting group tersebut. Belum lagi kesuburan rumput akan terganggu karena sering diinjak oleh pengguna sitting group tersebut.

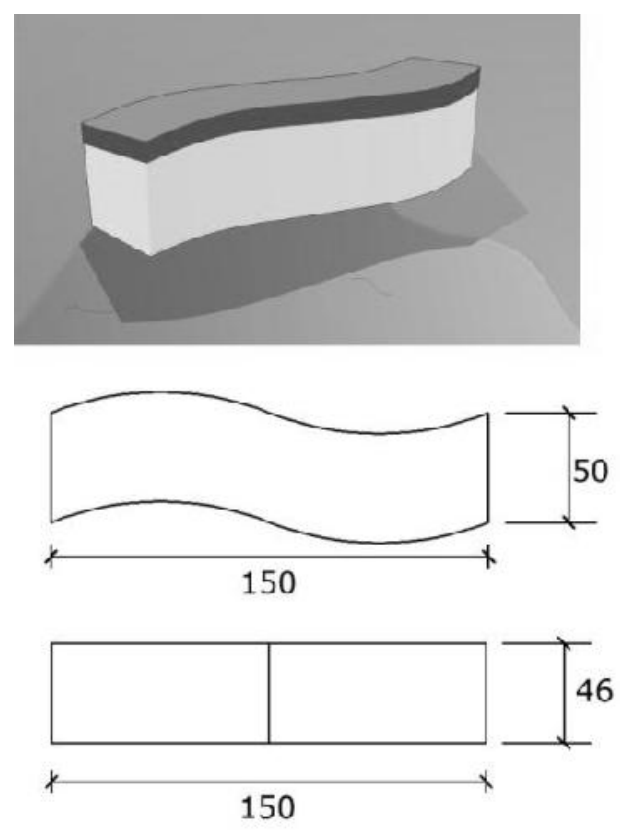

Gambar 1. Jenis sitting group lengkung 

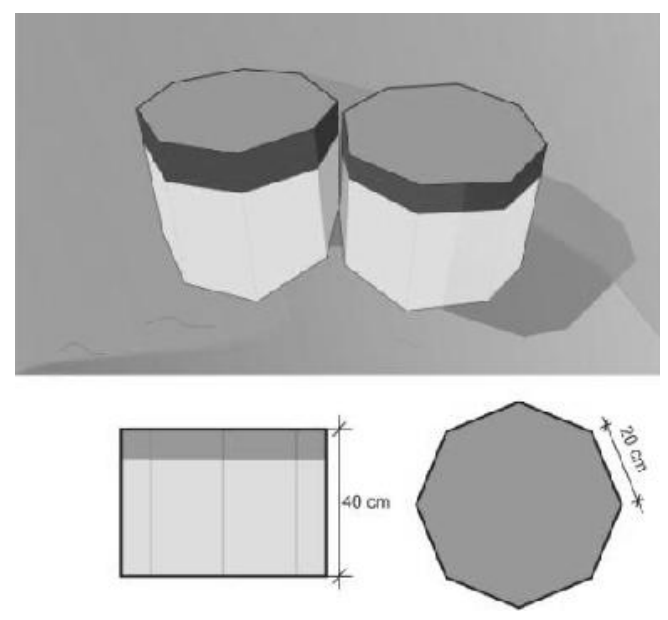

Gambar 2. Jenis sitting group segi enam

group jenis persegi panjang memiliki panjang 1.9 meter yang kemungkinan bisa dijadikan tempat tidur oleh para pengunjung maupun para tuna wisma. Memiliki ketinggian $40 \mathrm{~cm}$ artinya pada sitting group desain persegi panjang ini sudah memenuhi standar kenyamanan orang duduk.

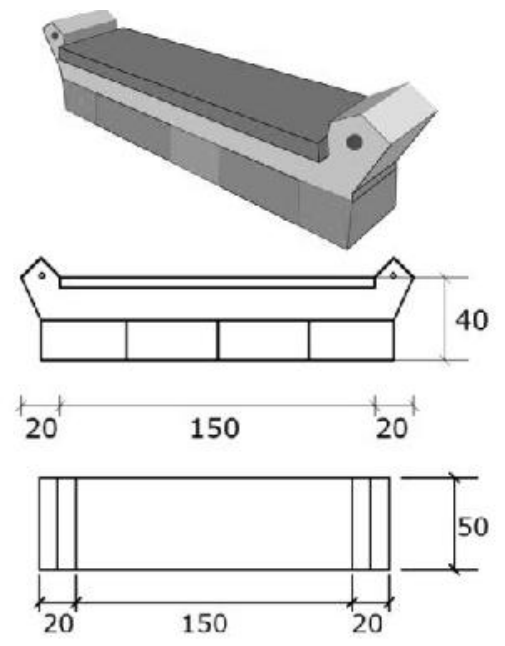

Gambar 3. Jenis sitting group panjang

\section{b. Open Stage}

Banyak sepeda motor yang memasuki area open stage (lihat Gambar 4).

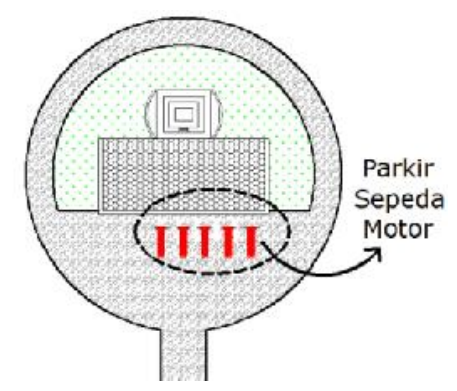

Gambar 4. Area Open Stage

\section{c. Jalur Pedestrian}

Area Jalur Pedestrian ini banyak terdapat Pedagang Kaki Lima (PKL) yang mengganggu aktifitas bagi pejalan kaki.

\section{d. Tempat Sampah}

Tempat sampah pada taman ini sudah tersedia dan sudah dipisahkan antara sampah organik dan sampah anorganik sesuai dengan anjuran pemerintah. Tempat sampah di taman ini berjumlah 7 pasang yang terbagi dalam beberapa titik di area taman.

e. Pot Tanaman

Pot tanaman pada taman ini digunakan untuk menanam tanaman seperti tanaman palm botol dan pucuk merah. Kondisi pot tanaman di taman ini masih layak dan masih bisa berfungsi sebagai elemen penghias di taman tersebut.

\section{f. Bak Tanaman}

Bak tanaman kurang terawat sehingga dijadikan tempat sampah bagi pengunjung (lihat Gambar 6).

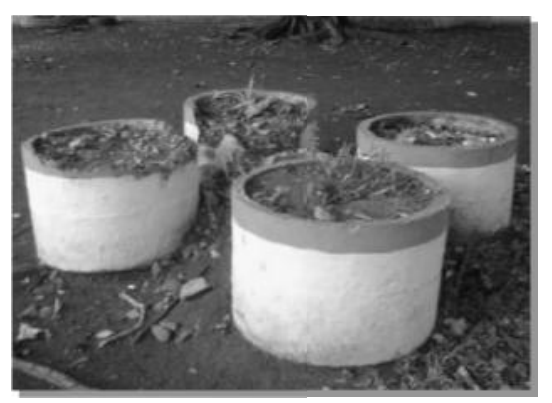

Gambar 5. Bak Tanaman 


\section{g. Lampu Taman}

Minimnya penerangan pada taman akan menimbulkan kriminalitas yang tinggi serta mengundang perbuatan asusila (lihat Gambar 7).

\section{h. Tempat Lampu}

Tempat lampu ini (lihat Gambar 8) seharusnya digunakan untuk lampu sorot namun sudah tidak terpakai lagi. Lampu sorot ini seharusnya menyinari patung pahlawan yang menjadi point of interest dari Taman Monumen 45.

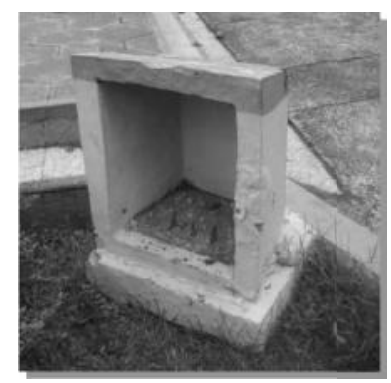

Gambar 6. Tempat Lampu

\section{i. Patung Pahlawan (Sculpture)}

Patung Pahlawan ini merupakan point of interest dari Taman Monumen 45. Namun,tidak adanya pencahayaan ke Patung Pahlawan menyebakan tidak terlihat pada malam hari (lihat Gambar 9)

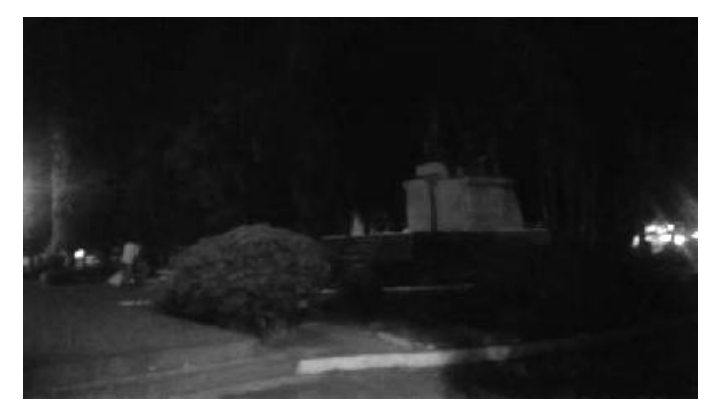

Gambar 7. Patung Pahlawan pada malam hari j. Toilet Umum

Taman Monumen 45 ini sudah memiliki Toilet umum sebagai sarana penunjang pada taman. Kondisi bangunan Toilet umum pada taman ini masih baik.

k. Papan Reklame dan Baliho

Papan Reklame dan Baliho pada Taman Monumen ini digunakan sebagai sarana untuk memberikan informasi. Kondisi Papan Reklame dan Baliho ini masih cukup baik. Namun untuk Baliho pada Taman ini letaknya dekat dengan tanaman peneduh sehingga baliho tersebut sedikit tertutupi pohon (lihat Gambar 10).

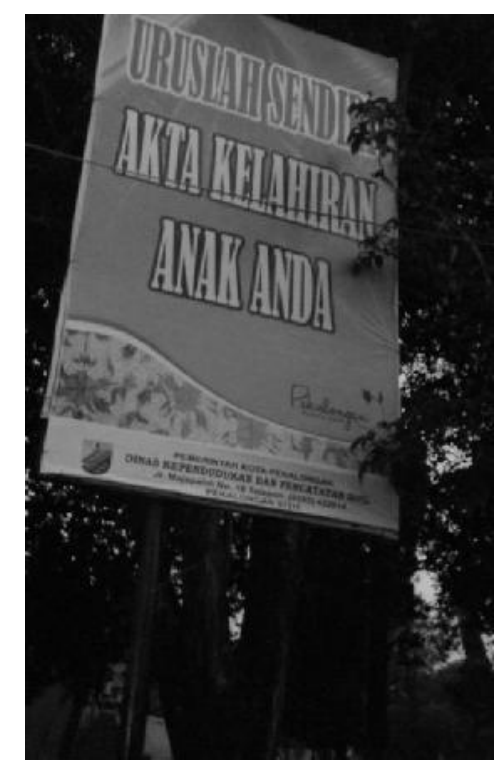

Gambar 8. Baliho

\section{Elemen Lunak (Soft Material)}

a. Tanaman Perdu

Jenis tanaman perdu yang berada di Taman Monumen 45 berupa tanaman tehtehan. Tanaman perdu di tanam ini dirawat dengan dengan baik, terlihat dari warna daunnya yang segar. 


\section{b. Tanaman Pengarah (Border)}

Tanaman border yang juga menjadi tanaman pengarah di Tanam Monumen 45 berupa pohon glodokan yang disusun berderet rapi di tepi jalur pedestrian. Pohon glodokan yang berderet rapi denga daun yang segar menunjukkan bahwa pohon ini terawat dengan baik.

\section{c. Tanaman Peneduh}

Tanaman peneduh yang terdapat di Tanam Monumen 45 berupa pohon tanjung dan pohon beringin. Pohon beringin dengn batang dan tajuknya yang besar sangat tepat dijadikan sebagai tanaman peneduh. Pohon beringin dan pohon tanjung yang terdapat di tanam ini cukup terawat dengan baik, hanya perlu dilakukan pemeliharaan seperti pemangkasan secara teratur agar tajuk pohon yang besar tidak mengesankan ruang di bawahnya terasa gelap.

\section{d. Tanaman Pelantai}

Tanaman pelantai yang digunakan yaitu rumput peking. Kondisi rumput peking ini sudah tidak terawat ditambah lagi tidak adanya stepping stone yang menuju ke area sitting group menyebabkan rumput terinjak-injak.

\section{e. Tanaman Hias}

Tanaman hias yang ada di Taman Monumen 45 ini diantaranya Bambu kuning, pohon cemara, pucuk merah, tanaman bougenvil dan puring.

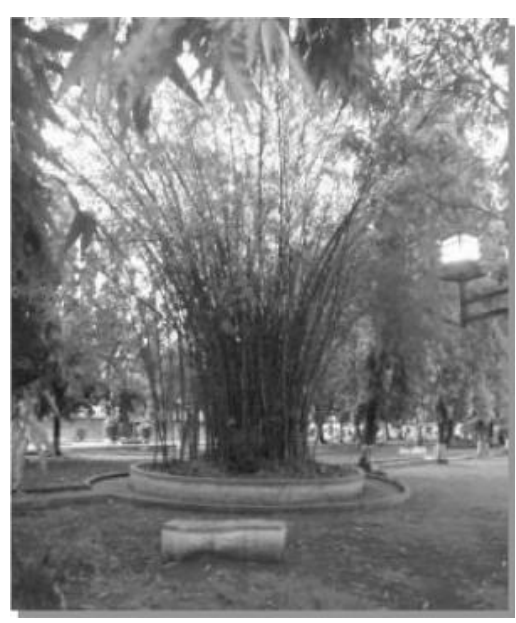

Gambar 9. Kondisi Tanaman hias bambu kuning

Kondisi tanaman ini kurang terawat. Selain itu tanaman bambu kuning yang seharusnya menjadi tanaman iconic (simbolik) sejarah senjata perjuangan untuk melawan penjajah memberikan kesan mistis. Kondisi tanaman bambu kuning yang sekarang ini mulai tumbuh liar tanpa adanya perawatan. Apalagi di area tersebut minim pencahayaan pada malam hari.

\section{f. Tanaman Palm-palman}

Di dalam Taman Monumen 45 ini terdapat tanaman palm-palman berupa pohon palm raja, palm wregu dan palm botol. Pohon palm raja selain berfungsi sebagai tanaman hias, pohon ini juga memiliki fungsi lain yaitu sebagai tanaman penyejuk udara, pohon palm wregu tahan terhadap udara dingin dan kering, sedangkan palm botol memiliki bentuk yang unik sehingga ketiganya sangat cocok menjadi salah satu pohon penghias taman. Tanaman palm-palman di taman Monumen 45 Kota Pekalongan cukup terawat dengan baik.

Dari hasil analisa pada elemen keras (Hard Material) dan elemen lunak (Soft Material) dapat diketahui layak atau tidaknya suatu elemen dari penilaian atau skoring berdasarkan kriteria sebagai berikut: 
A. Keindahan (bobot penilaian maksimal 10) Keindahan yang dimaksud dalam kriteria penilaian ini yaitu keindahan dari kondisi fisik elemen maupun keserasian antar elemen di dalam Taman Monumen $45 \mathrm{di}$ Kota Pekalongan ini.

B. Keterawatan (bobot penilaian maksimal 10)

Keterawatan dapat dilihat dari kondisi fisik elemen keras (hard material) dan elemen lunak (soft material)

C. Ketergunaan (bobot penilaian maksimal 10)

Ketergunaan yang dimaksud adalah keberadaan elemen baik elemen keras (hard material) maupun (soft material) sudah berfungsi sebagaimana mestinya atau mengalami perubahan fungsi bahkan tak berfungsi sama sekali.

D. Dimensi (bobot penilaian maksimal 10)
Dimensi dalam kriteria penilaian ini merupakan ukuran fisik elemen keras (hard material) maupun elemen lunak (hard material) yang ditinjau dari standar yang ada.

Dilihat dari hasil skoring rata-rata dari semua elemen berdasarkan kriteria yang ada (lihat Tabel 1), jumlah skor rata-rata adalah 4,66 maka dapat disimpulkan bahwa elemen pembentuk ruang komunal pada Taman Monumen 45 Kota Pekalongan masih tidak layak (skor $\leq 5$ dianggap tidak layak) hal ini karena beberapa elemen yang seharusnya ada, ternyata tidak ada pada taman ini. Hanya 3 elemen yang ada yang nilai skornya tidak layak, selebihnya adalah layak. Jadi berdasarkan nilai skor elemen-elemen pada taman ini yang ada, dapat dikatakan Taman Monumen 45 Pekalongan dalam kategori layak.

Tabel 1. Skoring Kelayakan Elemen Pembentuk Ruang Komunal di Taman Monumen 45 Kota Pekalongan

\begin{tabular}{|c|c|c|c|c|c|c|c|c|c|}
\hline \multirow[b]{2}{*}{ No. } & \multirow{2}{*}{$\begin{array}{c}\text { Standar Elemen } \\
\text { Taman }\end{array}$} & \multirow{2}{*}{$\begin{array}{c}\text { Elemen pada } \\
\text { Taman Monumen } 45\end{array}$} & \multicolumn{4}{|c|}{ Kriteria Penilaian } & \multirow{2}{*}{$\begin{array}{c}\text { Skor } \\
\text { Rata- } \\
\text { rata }\end{array}$} & \multicolumn{2}{|c|}{ Kelayakan } \\
\hline & & & $A$ & B & $\mathrm{C}$ & $\mathrm{D}$ & & $\begin{array}{c}\leq 5 \text { (tidak } \\
\text { layak) }\end{array}$ & $\begin{array}{c}>5 \\
\text { (layak) }\end{array}$ \\
\hline & Hard Material & & & & & & & & \\
\hline 1. & Sitting Group & Ada & 7 & 8 & 8 & 7 & 7.5 & & $\sqrt{ }$ \\
\hline 2. & Sport Area & Tidak ada & 0 & 0 & 0 & 0 & 0 & $\sqrt{ }$ & \\
\hline 3. & Area bermain & Tidak ada & 0 & 0 & 0 & 0 & 0 & $\sqrt{ }$ & \\
\hline 4. & Area Parkir & Tidak ada & 0 & 0 & 0 & 0 & 0 & $\sqrt{ }$ & \\
\hline 5. & Jogging track & Tidak ada & 0 & 0 & 0 & 0 & 0 & $\sqrt{ }$ & \\
\hline 6. & Jalur Pedestrian & Ada & 8 & 8 & 5 & 8 & 7.25 & & $\sqrt{ }$ \\
\hline 7. & Lampu Taman & Ada & 6 & 4 & 3 & 7 & 5 & $\sqrt{ }$ & \\
\hline 8. & Stepping Stone & Tidak ada & 0 & 0 & 0 & 0 & 0 & $\sqrt{ }$ & \\
\hline 9. & Area PKL & Tidak ada & 0 & 0 & 0 & 0 & 0 & $\sqrt{ }$ & \\
\hline 10. & Hotspot Area & Tidak ada & 0 & 0 & 0 & 0 & 0 & $\sqrt{ }$ & \\
\hline 11. & Open Stage & Ada & 7 & 8 & 2 & 7 & 6 & & $\sqrt{ }$ \\
\hline 12. & Signing & Ada & 6 & 6 & 7 & 8 & 6.75 & & $\sqrt{ }$ \\
\hline 13. & Sculpture & Ada & 9 & 8 & 8 & 8 & 8.25 & & $\sqrt{ }$ \\
\hline 14. & Tempat Sampah & Ada & 7 & 7 & 7 & 8 & 7.25 & & $\sqrt{ }$ \\
\hline 15. & Toilet & Ada & 6 & 8 & 7 & 8 & 7.25 & & $\sqrt{ }$ \\
\hline 16. & Bak Tanaman & Ada & 5 & 5 & 4 & 6 & 5 & $\sqrt{ }$ & \\
\hline 17. & Pot Tanaman & Ada & 7 & 8 & 8 & 8 & 7.75 & & $\sqrt{ }$ \\
\hline & Soft Material & & & & & & & & \\
\hline 18. & Tanaman Pelantai & Ada & 5 & 4 & 7 & 6 & 5.5 & & $\sqrt{ }$ \\
\hline 19. & Tanaman Border & Ada & 8 & 8 & 7 & 4 & 6.75 & & $\sqrt{ }$ \\
\hline 20. & Tanaman Peneduh & Ada & 8 & 8 & 8 & 8 & 8 & & $\sqrt{ }$ \\
\hline 21. & Tanaman Perdu & Ada & 7 & 8 & 8 & 8 & 7.75 & & $\sqrt{ }$ \\
\hline
\end{tabular}




\begin{tabular}{|c|l|c|c|c|c|c|c|c|c|}
\hline 22. & Palm-palman & Ada & 8 & 8 & 7 & 6 & 7.25 & & $\sqrt{ }$ \\
\hline 23. & Tanaman Hias & Ada & 4 & 3 & 4 & 5 & 4 & $\sqrt{ }$ & \\
\hline & Skoring Rata-rata & & & & 4,66 & & \\
\hline
\end{tabular}

\section{KESIMPULAN}

Berdasarkan hasil penelitian dan analisis yang telah dilaksanakan, maka peneliti dapat menarik kesimpulan sebagai berikut:

1. Berdasarkan hasil skoring akhir yang didapat terhadap elemen pembentuk ruang komunal di Taman Monumen 45 Kota Pekalongan secara umum dinyatakan masih tidak layak walaupun masih ada beberapa elemen yang dikategorikan layak. Namun terhadap skoring elemen yang ada pada taman ini, dapat dikatakan taman ini masih layak.

2. Taman Monumen 45 sebenarnya berpotensi menjadi ruang terbuka hijau yang ramai pengunjung dan menjadi ciri khas dari Kota Pekalongan, akan tetapi Pemerintah Kota belum secara optimal melaksanakan tindakan perawatan dan pemeliharaan taman.

Setelah dilaksanakannya observasi dan analisa mengenai Taman Monumen 45, tentuya terlihat beberapa masalah yang terjadi pada taman tersebut, maka terdapat beberapa saran yang dapat dipertimbangkan untuk menjadikan Taman Monumen 45 Kota Pekalongan lebih baik dari sebelumnya.

1. Pemerintah Kota Pekalongan, khususnya Dinas Pertamanan seharusnya lebih memperhatikan lagi potensi-potensi yang ada di Taman Monumen 45 dan diadakan penambahan, pemeliharaan dan perawatan elemen-elemen yang ada pada Taman Monumen 45 agar untuk memberikan kenyamanan kepada para pengunjung.

2. Adanya sifat rasa memiliki baik Pemerintah Kota maupun pengunjung tentunya akan sangat membantu dalam menjaga dan memelihara salah satu taman kota yang dimiliki Kota Pekalongan ini.

\section{UCAPAN TERIMAKASIH}

Penelitian ini dilaksanakan atas bantuan dari berbagai pihak, untuk itu penulis mengucapkan terimakasih kepada Saudara Siti Amaliyah, Irma Yustika, Sukma Setya Shinta dan pihak-pihak lain yang tidak dapat kami sebutkan satu-persatu atas bantuannya, sehingga penelitian ini dapat terlaksana dengan baik.

\section{DAFTAR PUSTAKA}

Arifin. 2006. Elemen Taman

Bell, Paul A., Thomas C. Greene, Jeffrey D. Fisher, \& Andrew Baum. 2001. Environmental psychology. Canada: Thomson Wardsworth.

Simonds, John Ormsbee. 1994. Garden cities 21: creating a livable urban environment. New York: McGraw-Hill.

Woolley, Helen. 2003. Urban open space. London: Spon Press. 